\title{
Türkiye'de Elektrik Tüketiminde Talep Tahmini: Zaman Serisi Ve Regresyon Analizi İle Karşılaştırma
}

\author{
Emine Elif Nebati ${ }^{1 *}$, Murat Taş${ }^{2}$, Gamze Ertaş ${ }^{3}$ \\ 1* İstanbul Sabahattin Zaim Üniversitesi, Mühendislik ve Doğa Bilimleri Fakültesi, Endüstri Mühendisliği Bölümü, İstanbul, Türkiye, (ORCID: 0000-0002-3950- \\ 4279), emine.nebati@izu.edu.tr \\ 2 İstanbul Sabahattin Zaim Üniversitesi, Mühendislik ve Doğa Bilimleri Fakültesi, Endüstri Mühendisliği Bölümü, İstanbul, Türkiye, (ORCID: : 0000-0003-3964- \\ 536X), murat_ttas@hotmail.com \\ 3 İstanbul Sabahattin Zaim Üniversitesi, Mühendislik ve Doğa Bilimleri Fakültesi, Endüstri Mühendisliği Bölümü, İstanbul, Türkiye, (ORCID: 0000-0002-0562-6294), \\ gamzertas98@gmail.com
}

(İlk Geliş Tarihi 21 Eylül 2021 ve Kabul Tarihi 10 Aralık 2021)

(DOI: 10.31590/ejosat.998277)

ATIF/REFERENCE: Nebati, E. E., Taş, M. \&Ertaş, G. (2021). Türkiye'de Elektrik Tüketiminde Talep Tahmini: Zaman Serisi Ve Regresyon Analizi İle Karşılaştırma. Avrupa Bilim ve Teknoloji Dergisi, (31), 348-357.

$\ddot{O} \mathbf{z}$

Değişen Dünya koşullarında ve artan nüfusa bağlı olarak, Ülkelerin ekonomik ve sosyal süreçlerinin gelişmesinin en temel ihtiyaçlardan biri, enerjidir. Tüketimin artması sonucu, kaynakların kısıtlı olması ve sanayileşmenin de getirmiş olduğu çeşitli ihtiyaçlar, insanların taleplerinin değişmesine ve farklı sınıflara ayrılmasına neden olmuştur. Firmalar ve kurumlar bu çeşitlilik artışı sonucunda doğrudan etkilenmiş, üretim artmış ve bu sayede ülkelerde ekonomik bakımdan kalkınmıştır. Üretimde dışa bağımlılık, ürünlerin ve bazı enerji kaynaklarının önceden tahmininin yapılması arz- talep dengesi açısından son derece önem teşkil etmektedir. Elektrik enerjisinin depolanma imkânları kısıtlıdır. Bu nedenle, talep miktarına göre enerji üretimi yapılması, kritik derecede öneme sahiptir. Aksi halde talepten fazla gerçekleşen alımlarda depolama kısıtından dolayı kaynak israfına ve devletlerin borçlanmasına sebep olabilmektedir. geleceğe yönelik talep tahminlerinin doğru yapılması kaynakların doğru yönetilmesi bakımından önem taşımaktadır. Bu çalışmada, Türkiye'de ki elektrik tüketim verileri doğrultusunda, regresyon analizi ve zaman serisi tekniklerinden faydalanılarak talep tahmini analizi yapılmıştır. Elde edilen veriler sonucunda, TÜİK tarafından alınan var olan değerler ile regresyon ve zaman serisi sonucunda yapmış olduğumuz talep tahmin sonuçlarının birbirlerine yakın olduğu gözlemlenmiştir.

Anahtar Kelimeler: Talep Tahmini, Zaman Serisi, Regresyon, Enerji

\section{Demand Forecasting for Electricity Consumption in Turkey: Comparison with Time Series and Regression Analysis}

\begin{abstract}
Depending on the changing world conditions and increasing population, one of the most basic needs for the development of the economic and social processes of countries is energy. As a result of increased consumption, limited resources and various needs brought by industrialization, people's demands have changed and they have been divided into different classes. Firms and institutions have been directly affected by this increase in diversity, production has increased and countries have developed economically. Foreign dependency in production, forecasting of products and some energy resources is extremely important in terms of the balance. of supply demand. The storage possibilities of electrical energy are limited. Therefore, it is critically important to produce energy according to the amount of demand. Otherwise, more supply than demand may cause waste of resources and borrowing of states due to storage constraints. Making accurate forecasts of future demand is important for the correct management of resources. In this study, demand forecasting analysis has been made by using regression analysis and time series techniques using electricity consumption data in Turkey. As a result of the study, it has been observed that the existing values obtained by TÜIKK and the demand forecast results we reached as a result of regression and time series are close to each other.
\end{abstract}

Keywords: Demand Forecast, Time Series, Regression, Energy

*Corresponding Author: emine.nebati@izu.edu.tr, 


\section{Giriş}

Türkiye'de hızla büyüyen sanayi ve artan nüfus oranı ile birlikte enerji ihtiyacı da hergeçen gün artmaktadır. Dışa bağımlı olma noktasında, arz- talep dengesini sağlamak ve enerji talebinin önceden tahmin edilmesi Türkiye için son derece önemlidir. Oluşan arzın, talebe göre fazla olması durumunda enerji açığına bağlı olarak kesintiler ve çeşitli problemler yaşanacaktır. Talebin, arza göre fazla olması durumunda da depolama sorunundan kaynaklı israflara ve dış borçlanma gibi ülke politikalarını derinden etkileyebilecek sorunlara neden olmaktadır. Dolayısıyla, talep tahmini dengeyi sağlama noktasında büyük önem taşımaktadır.

Devletlerin bu noktada ekonomilerini güçlendirmek ve halkların ihtiyaçlarını karşılayabilmesi açısından gelecek dönemler için tahminlerde bulunması buna bağlı olarak ataklar ve planlar yapması kaçınılmaz bir gereksinimdir. Yapılan bu tahminerin doğrulukları yönünde karar verme ve planlama aşamaları ülkelerin ekonomisine domino etkisi yaratarak varlıklarını sürdürebilmeleri ve büyüyebilmeleri açısından önemli rol oynamaktadir.

Her ülkenin enerji ihtiyacı vardır ve bunları karşılamak için doğal kaynakları yeterli olmayabilir. $\mathrm{Bu}$ yüzden oluşan enerji açığını karşılayabilmek için dışarıya bağımlı konuma gelebilmektedirler. Elektrik enerjisinin bu noktada büyük ölçüde depolanamadığından talep tahminlemesi oldukça önemlidir. $\mathrm{Bu}$ çalışmada, Türkiye'de ki elektrik tüketim verileri doğrultusunda, regresyon analizi ve zaman serisi tekniklerinden faydalanılarak talep tahmini analizi yapılmıştır. Elde edilen veriler sonucunda, TÜİK tarafından alınan var olan değerler ile regresyon ve zaman serisi sonucunda yapmış olduğumuz talep tahmin sonuçlarının birbirlerine yakın olduğu gözlemlenmektedir.

Çalışmada öncelikle, özellikle son yıllarda enerji alanındaki araştırmalar incelenmişitr. Sonrasında Elektrik enerjisinin de genel görünümüne yer verildikten sonra Türkiye'de ki duruma değinilmiştir. Üçüncü bölümde, araştırma metodolojisine kısaca değinildikten sonra uygulama bölümü hazırlanmış ve sonuçlar analiz edilmiştir.

Talep tahmini, enerji, zaman serisi, regresyona yönelik literatürde çeşitli çalışmalar bulunmaktadır. Son yıllarda, yazındaki bazı ulusal ve uluslararası çalışmalara Tablo 1'de verilmiştir. Erdoğdu (2007) çalışmasında, eşbütünleşme analizi ve ARIMA modeli ile elektrik talep tahmini gerçekleştirmiş ve analiz sonuçlarını Enerji ve Tabii Kaynaklar Bakanlığı resmi verileri ile karşılaştırılmıştır. Modelde, 1923-2004 yıllarındaki elektrik tüketim değerleri (GWh) değerlendirilmiş, sonrasında model doğrulaması için 2000-2004 yıllarında, elektrik talebi tahmini yapılarak, tahmin sonuçları gerçek tüketim değerleri ile karşılaştırılmıştır (Erdoğdu, 2007). Hamzaçebi (2007) çalışmasında, Türkiye'nin net elektrik tüketimini 2020 yılına kadar analiz etmiştir. Araştırmada, sektör bazında 1970-2004 aralığında yıllık elektrik tüketim değerlerini ayırmış ve yapay sinir ağ1 yöntemi ile modelleme kurmuştur (Hamzaçebi, 2007). Altınay (2010) çalışmasında, Türkiye için aylık toplam elektrik tüketimlerini (GWh)ve 1995-2008 yıllarındaki veriler ele alınarak, 2009 yılı için aylık talep tahmini yapmıştır. Gün uzunluğu, hava koşulları, iktisadi faaliyetler gibi mevsimsel etkiler taşıyan tüketimin modellenmesi için bu araştırmada ARIMA modeli tercih edilmiştir. (Altınay, 2010). Demirel vd. (2010) çalışmada, 1970-2007 yılları aralığında üretilen enerji, ,GSMH, kurulu güç, tüketilen enerji, ve nüfus verileri ile ARIMA ve adaptif ağ tabanlı bulanık çıkarım sistemi (ANFIS) yöntemlerini kullanmış ve talep tahmin modellerini kurmuşlardır. Kurulan modeller ile, 2006-2010 yılları arası elektrik talep tahminleri yapılmıştır (Demirel vd., 2010). Al-Hafid ve Almaamary (2012) çalışmada, Irak'ın günlük elektrik tüketim verileri ile elektrik talep tahmini yapmışlardır. Zaman serileri analizinde Holt-Winters metodu tercih edilmiştir (Al-Hafid ve Almaamary 2012). Kheirkhah ve diğerleri 2013 yılında, elektrik tüketimindeki hem mevsimsel hem aylık tahmin değişikliklerini analiz etmek için Yapay Sinir A $\breve{g} 1$ (YSA), Temel Bileşen Analizi (PCA), Veri Zarflama Analizi (DEA) ve ANOVA gibi çeşitli yöntemler kullanmışlardır ( Kheirkhah ve diğerleri 2013). Liu ve diğerleri 2014 yılında, sıcaklık faktörüne göre kısa vade elektrik yükü tahmini için SARIMAX ve YSA olmak üzere iki çeşit model önermiştir (Liu ve diğerleri 2014). Ozoh ve diğerleri 2014 yılında, Malezya'da bir devlet üniversitesinin verilerini kullanarak farklı değişkenler için, elektrik tüketimini 2009-2012 yıllarını için tahmin etmiştir ( Ozoh ve diğerleri, 2014). Mahmutoğlu ve Öztürk (2015) çalışmalarında, 1970-2011 yıllarındaki elektrik tüketim verileri ile Türkiye için 2015-2023 yılları arası brüt elektrik talep tahmini yapmışlardır. ARMA tahmin modeli tercih edilmiştir (Mahmutoğlu ve Öztürk, 2015). Hussain vd. (2016) çalışmada, 1980-2011 yılları arası günlük elektrik tüketim verileri ile sektörel olarak 2012-2020 yılları için elektrik enerji talep öngörülerinde bulunulmuştur Holter Winter ve ARIMA yöntemleri tercih edilmiştir. (Hussain vd., 2016). Karaca ve Karacan 2016 yılında, regresyon analizi ile tahminleme çalışması yapmıştır. İnternet Kullanımı, Ortalama Yaşam Beklentisi, Gayri Safi Yurt İçi Milli Hasıla gibi bazı elektrik tüketimini etkileyen faktörleri değerlendirmiştir.( Karaca ve Karacan 2016).Son ve Kim (2017) çalışmada, Kuzey Kore'nin aylık elektrik tüketimlerini tahmin etmişlerdir. Araştırmada, yazın araştırması sonucunda aylık elektrik tüketimini çeşitli ekonomik, meteorolojik, ve demografik değişkenin etkilediği sonucuna varılmıştır (Son ve Kim, 2017). Başoğlu ve Bulut 2017 yılında, Türkiye'nin kısa dönemde elektrik talep tahmini için bir sistem geliştirerek araştırma yapmışlardır. Uzman sistemler ve yapay sinir ağları bütünleşik kullanılmıştır. Gayri safi milli hâsıla, sıcaklık, sanayi üretim endeksi gibi kriterler tahmin için karşılaştırılmıştır (Başoğlu ve Bulut, 2017).Toros ve Aydın 2018 yılındaki çalışmada, 2012- 2016 yıllarında Türkiye'de kısa dönemli elektrik tüketimi ile sıcaklık ilişkisi analiz edilmiştir. Yapay Sinir Ağı (YSA) yöntemi kullanılmıştır (Toros ve Aydın 2018). Çiçek ve Lecuna 2019 yılındaki çalışmada, Türkiye'deki bölgeleri baz alarak elektrik tüketim etkinliğini VZA tekniği ile değerlendirmiştir. Değerlendirmede, tüketici sayısı, sanayi, aydınlatma gibi faktörleri göz önünde bulundurmuştur. Bölgeler arsında verimlilik açısından en iyi sonuç Akdeniz bölgesi olarak gözlenmiştir. Erkınay 2021 yılında, yapay sinir ağları kullanarak İskenderun için aylık enerji tüketim tahmini gerçekleştirmiş ve kurulan modelin büyük devlet tesislerinin ve özellikle yenilenebilir enerji teknoloji alanında yatırım yapanların faydalanabileceğini belirtmiştir (Erkınay Özdemir, 2021).Ülkü ve Yalpır 2021 yılındaki çalışmada, coğrafi bölgelere göre 2030 yılı için elektrik enerjisi tahmini için analiz gerçekleştirmiştir..Nüfüs, eğitim durumu, gayri safi yurtiçi hasıla,ihricat gibi kriterleri değerlendirmede kullanmıştır.( Ülkü ve Yalpır 2021). 
Tablo 1. 2007-2020 enerji alanında talep tahmini çalışmaları

\begin{tabular}{|c|c|c|c|c|c|c|}
\hline Yıl & Yazar Soyadı & Makale adı & $\begin{array}{l}\text { Yayınlandığı } \\
\text { yer }\end{array}$ & $\begin{array}{l}\text { Uygula } \\
\text { ma } \\
\text { alanı }\end{array}$ & Çalışmanın amacı & $\begin{array}{l}\text { Kullanılan } \\
\text { yöntemi }\end{array}$ \\
\hline 2007 & Hamzaçebi & $\begin{array}{l}\text { Forecasting of Turkey's net } \\
\text { electricity energy consumption } \\
\text { on sectoral bases. }\end{array}$ & Energy Policy & Enerji & $\begin{array}{l}\text { Türkiye'de net enerji } \\
\text { talebinin tahmin edilmesi }\end{array}$ & YSA \\
\hline 2007 & Erdoğdu & $\begin{array}{l}\text { Electricity demand analysis } \\
\text { using cointegration and } \\
\text { ARIMA modelling: A case } \\
\text { study of } \\
\text { Turkey }\end{array}$ & Energy Policy & Enerji & $\begin{array}{l}\text { Türkiye' de elektrik talep } \\
\text { tahmini yapılmas1 }\end{array}$ & ARIMA \\
\hline 2008 & $\begin{array}{l}\text { Taylor ve } \\
\text { Mcsharry }\end{array}$ & $\begin{array}{l}\text { Short-term load forecasting } \\
\text { methods: An evaluation based } \\
\text { on european data }\end{array}$ & $\begin{array}{l}\text { Digital Object } \\
\text { Identifier }\end{array}$ & Enerji & $\begin{array}{l}10 \text { Avrupa ülkesinin } \\
\text { elektrik talep tahmini için } \\
\text { Holt-Winters ve Arıma ve } \\
\text { yöntemlerinden } \\
\text { hangisinin daha uygun } \\
\text { olduğunu gözlemlemek }\end{array}$ & $\begin{array}{l}\text { ARIMA, HOLT- } \\
\text { WINTERS }\end{array}$ \\
\hline 2009 & $\begin{array}{l}\text { Toker ve } \\
\text { Korkmaz }\end{array}$ & $\begin{array}{l}\text { Türkiye kısa süreli elektrik } \\
\text { talebinin saatlik olarak tahmin } \\
\text { edilmesi }\end{array}$ & $\begin{array}{l}\text { Elektrik } \\
\text { Mühendisleri } \\
\text { Odas1 Sitesi }\end{array}$ & Enerji & $\begin{array}{l}\text { Kisa vadeli elektrik } \\
\text { tüketimini tahmin etmek }\end{array}$ & YSA ve ARIMA \\
\hline 2010 & $\begin{array}{l}\text { Demirel ve } \\
\text { arkadaşları }\end{array}$ & $\begin{array}{l}\text { Anfis ve Arma modelleri ile } \\
\text { elektrik enerjisi yük tahmini }\end{array}$ & $\begin{array}{l}\text { Gazi Üniversitesi } \\
\text { Mühendislik } \\
\text { Mimarlık } \\
\text { Fakültesi Dergisi }\end{array}$ & Enerji & $\begin{array}{l}\text { Y1llı elektrik üretimini } \\
\text { ve tüketimini tahmin } \\
\text { etmek }\end{array}$ & $\begin{array}{l}\text { ARMA } \\
\text { ANFIS }\end{array}$ \\
\hline 2010 & Altınay & $\begin{array}{ll}\text { Aylık elektrik } & \text { talebinin } \\
\text { mevsimsel model } & \text { ile orta } \\
\text { dönem öngörüsü } & \end{array}$ & $\begin{array}{l}\text { Enerji, Piyasa ve } \\
\text { Düzenleme }\end{array}$ & Enerji & Aylık elektrik tüketimi & ARIMA \\
\hline 2012 & $\begin{array}{l}\text { Al-Hafid ve } \\
\text { Al-maamary }\end{array}$ & $\begin{array}{l}\text { Short term electrical load } \\
\text { forecasting using holtwinters } \\
\text { method. }\end{array}$ & $\begin{array}{l}\text { AL Rafdain } \\
\text { Engineering } \\
\text { Journal }\end{array}$ & Enerji & $\begin{array}{l}\text { Irak'da ki günlük elektrik } \\
\text { tüketim verileri ile } \\
\text { elektrik talep tahmini } \\
\text { yap1lması }\end{array}$ & $\begin{array}{l}\text { Zaman Serisi } \\
\text { Holt-Winters }\end{array}$ \\
\hline 2013 & $\begin{array}{l}\text { Kheirkhah ve } \\
\text { diğerleri }\end{array}$ & $\begin{array}{l}\text { Improved estimation of } \\
\text { electricity demand function by } \\
\text { using of artificial neural } \\
\text { network, principal component } \\
\text { analysis and data envelopment } \\
\text { analysis }\end{array}$ & $\begin{array}{l}\text { Computers } \\
\text { Industrial } \\
\text { Engineering }\end{array}$ & Enerji & $\begin{array}{l}\text { Elektrik tüketimindeki } \\
\text { hem mevsimsel hem aylık } \\
\text { tahmin değişikliklerini } \\
\text { analiz edilmesi }\end{array}$ & $\begin{array}{l}\text { YSA, PCA, Veri } \\
\text { Zarflama Analizi } \\
\text { ve ANOVA }\end{array}$ \\
\hline 2014 & $\begin{array}{l}\text { Es ve } \\
\text { arkadaşları }\end{array}$ & $\begin{array}{l}\text { Yapay sinir ağları ile Türkiye } \\
\text { net enerji talep tahmini }\end{array}$ & Gazi Üniversitesi & Enerji & $\begin{array}{l}\text { Türkiye'de net enerji } \\
\text { talep tahmini }\end{array}$ & $\begin{array}{l}\text { Çoklu Doğrusal } \\
\text { Regresyon YSA }\end{array}$ \\
\hline 2014 & $\begin{array}{l}\text { Ozoh ve } \\
\text { diğerleri }\end{array}$ & $\begin{array}{l}\text { Comparative Analysis of } \\
\text { Techniques for Forecasting } \\
\text { Electricity Consumption, }\end{array}$ & $\begin{array}{l}\text { Int. Journal of } \\
\text { Computer } \\
\text { Applications }\end{array}$ & Enerji & $\begin{array}{lr}\text { Malezya'da } & \text { bir } \\
\text { üniversitenin } & \text { elektrik } \\
\text { tüketim tahmini } & \end{array}$ & $\begin{array}{l}\text { Zaman seisi, } \\
\text { YSA, } \\
\text { Değiştirilmiş } \\
\text { Newton yöntemi }\end{array}$ \\
\hline 2014 & $\begin{array}{l}\text { Liu ve } \\
\text { arkadaşları }\end{array}$ & $\begin{array}{l}\text { Short-Term Forecasting of } \\
\text { Temperature Driven Electricity } \\
\text { Load Using Time Series and } \\
\text { Neural Network Model }\end{array}$ & $\begin{array}{l}\text { Journal of Clean } \\
\text { Energy } \\
\text { Technologies }\end{array}$ & Enerji & $\begin{array}{l}\text { Elektrik yükü kısa vadeli } \\
\text { tahmini }\end{array}$ & SARIMAX,YSA \\
\hline 2015 & $\begin{array}{l}\text { Mahmutoğlu } \\
\text { ve Öztürk }\end{array}$ & $\begin{array}{lrr}\text { Türkiye } & \text { elektrik } & \text { tüketimi } \\
\text { öngörüsü ve bu } & \text { kapsamda } \\
\text { geliştirilebilecek } & \text { politika } \\
\text { önerileri } & \\
\end{array}$ & $\begin{array}{l}\text { Gazi } \\
\text { Üniversitesi, } \\
\text { Ekonomik } \\
\text { Yaklaşım Dergisi } \\
\end{array}$ & Enerji & $\begin{array}{l}\text { Türkiye'de } 2015-2023 \\
\text { aralığında brüt elektrik } \\
\text { talep tahmini yapılması }\end{array}$ & ARIMA \\
\hline 2017 & Son ve Kim & $\begin{array}{l}\text { Short-term forecasting of } \\
\text { electricity demand for the } \\
\text { residential sectorusing weather } \\
\text { and social variable }\end{array}$ & $\begin{array}{l}\text { Resources, } \\
\text { Conservation and } \\
\text { Recycling }\end{array}$ & Enerji & $\begin{array}{lcr}\text { Konut } & \text { sektöründeki bir } \\
\text { aylik } & \text { elektrik } & \text { talebi } \\
\text { tahmini } & \text { için } & \text { model } \\
\text { sunmak } & & \end{array}$ & $\begin{array}{l}\text { YSA } \\
\text { ARIMA, Çoklu } \\
\text { Doğrusal } \\
\text { Regresyon } \\
\text { (MLR) }\end{array}$ \\
\hline 2017 & $\begin{array}{l}\text { Bulut ve } \\
\text { Başoğlu }\end{array}$ & $\begin{array}{l}\text { Kisa Dönem Elektrik Talep } \\
\text { Tahminleri İçin Yapay Sinir } \\
\text { Ağları ve Uzman Sistemler } \\
\text { Tabanlı Hibrid Tahmin Sistemi } \\
\text { Geliştirilmesi }\end{array}$ & $\begin{array}{l}\text { Gazi Üniversitesi } \\
\text { Mühendislik } \\
\text { Mimarlık } \\
\text { Fakültesi Dergisi }\end{array}$ & Enerji & $\begin{array}{l}\text { Kısa dönem elektrik talep } \\
\text { tahminleri yaparak yeni } \\
\text { yöntemlerlegeleceğe } \\
\text { dönük öneriler sunulması }\end{array}$ & $\begin{array}{lr}\text { Yapay } & \text { sinir } \\
\text { ağları, } & \text { Uzman } \\
\text { sistem( } & \text { EPSIM- } \\
\text { NN sistemi) }\end{array}$ \\
\hline
\end{tabular}


European Journal of Science and Technology

\begin{tabular}{|c|c|c|c|c|c|c|}
\hline 2016 & $\begin{array}{l}\text { Hussain ve } \\
\text { arkadaşları }\end{array}$ & $\begin{array}{l}\text { Forecasting } \\
\text { consumption in Pakistan: the } \\
\text { way forward }\end{array}$ & Energy Policy & Enerji & $\begin{array}{l}\text { Pakistan'da artan elektrik } \\
\text { kesintilerinin olumsuz } \\
\text { etkileri }\end{array}$ & $\begin{array}{l}\text { Holter Winter Ve } \\
\text { Arıma }\end{array}$ \\
\hline 2016 & $\begin{array}{l}\text { Karaca ve } \\
\text { Karacan }\end{array}$ & $\begin{array}{lr}\text { Çoklu regresyon } & \text { metoduyla } \\
\text { elektrik tüketim } & \text { talebini } \\
\text { etkileyen } & \text { faktörlerin } \\
\text { incelenmesi } & \end{array}$ & $\begin{array}{l}\text { Selçuk } \\
\text { Üniversitesi } \\
\text { Mühendislik, } \\
\text { Bilim ve } \\
\text { Teknoloji } \\
\text { Dergisi }\end{array}$ & Enerji & $\begin{array}{l}\text { elektrik talep } \\
\text { etkileyen veriler program } \\
\text { gelisstirilerek } \\
\text { edilmesi }\end{array}$ & $\begin{array}{l}\text { Basit ve Çoklu } \\
\text { Regresyon }\end{array}$ \\
\hline 2018 & $\begin{array}{l}\text { Yüksel } \\
\text { Haliloğlu ve } \\
\text { Tutu }\end{array}$ & $\begin{array}{l}\text { Türkiye için kisa vadeli } \\
\text { elektrik enerjisi talep tahmini }\end{array}$ & $\begin{array}{l}\text { Yaşar } \\
\text { Üniversitesi }\end{array}$ & Enerji & $\begin{array}{lr}\text { Türkiye } & \text { elektrik } \\
\text { tüketimini } & \text { günlük } \\
\text { tahminleyebilecek } & \text { bir } \\
\text { model kurulmasi } & \\
\end{array}$ & $\begin{array}{l}\text { Regresyon } \\
\text { Analizi }\end{array}$ \\
\hline 2018 & $\begin{array}{l}\text { Aydın ve } \\
\text { Toros }\end{array}$ & $\begin{array}{l}\text { Prediction of Short-Term } \\
\text { Electricity Consumption by } \\
\text { Artificial Neural Networks } \\
\text { Using Temperature Variables }\end{array}$ & $\begin{array}{l}\text { Avrupa Bilim ve } \\
\text { Teknoloji } \\
\text { Dergisi }\end{array}$ & Enerji & $\begin{array}{lr}\text { Türkiye'de } & \text { elektrik } \\
\text { tüketimi ile } & \text { sicaklık } \\
\text { arasındaki } & \text { ilişki } \\
\text { incelenmesi } & \\
\end{array}$ & YSA \\
\hline 2019 & $\begin{array}{l}\text { Çiçek ve } \\
\text { Lecuna }\end{array}$ & $\begin{array}{lr}\text { Türkiye'deki } & \text { Bölgelerin } \\
\text { Elektrik } & \text { Tüketim } \\
\text { Etkinliklerinin Veri Zarflama } & \text { Analizi ile Değerlendirilmesi }\end{array}$ & $\begin{array}{l}\text { Akıllı Ulaşım } \\
\text { Sistemleri ve } \\
\text { Uygulamaları } \\
\text { Dergisi }\end{array}$ & Enerji & $\begin{array}{lr}\text { Türkiye'deki } 7 \text { Bölge'nin } \\
\text { elektrik } & \text { tüketimi } \\
\text { etkinliğinin } & \\
\text { karşılaştırması } & \end{array}$ & $\begin{array}{l}\text { Veri Zarflama } \\
\text { Analizi }\end{array}$ \\
\hline 2020 & $\begin{array}{l}\text { Özkan ve } \\
\text { arkadaşları }\end{array}$ & $\begin{array}{l}\text { Elektrik enerjisi tüketim } \\
\text { verileri için uygun tahmin } \\
\text { yöntemi seçimi }\end{array}$ & $\begin{array}{ll}\text { Journal } & \text { of } \\
\text { Industrial } & \\
\text { Engineering } & \end{array}$ & Enerji & $\begin{array}{l}\text { Enerji verilerine bakarak } \\
\text { en uygun talep tahmin } \\
\text { yöntemini bulmak }\end{array}$ & $\begin{array}{l}\text { Fourier Analizi, } \\
\text { En Küçük } \\
\text { Kareler } \\
\text { Yöntemi, } \\
\text { Winters }\end{array}$ \\
\hline 2020 & $\begin{array}{l}\text { Jiang ve } \\
\text { arkadaşları }\end{array}$ & $\begin{array}{l}\text { Holt-Winters } \\
\text { smoothing } \\
\text { enhanced by fruit fly } \\
\text { optimization algorithm to } \\
\text { forecast monthly electricity } \\
\text { consumption. }\end{array}$ & Energy & Enerji & $\begin{array}{l}\text { Çin'in aylı elektrik } \\
\text { tüketim verileri ile } \\
\text { tahminleme yapılması }\end{array}$ & $\begin{array}{l}\text { Meyve } \\
\text { Sineği } \\
\text { Algoritmas1, } \\
\text { Holt-Winters } \\
\text { yöntemi }\end{array}$ \\
\hline 2021 & $\begin{array}{l}\text { Erkınay } \\
\text { Özdemir }\end{array}$ & 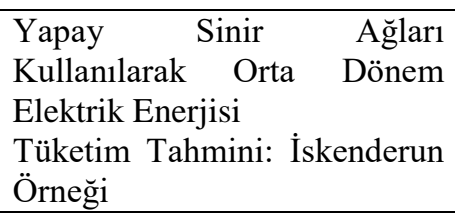 & $\begin{array}{l}\text { Avrupa Bilim ve } \\
\text { Teknoloji } \\
\text { Dergisi }\end{array}$ & Enerji & $\begin{array}{l}\text { İskenderun için aylik } \\
\text { enerji tüketim tahmini }\end{array}$ & YSA \\
\hline 2021 & $\begin{array}{l}\text { Ülkü ve } \\
\text { Yalpır }\end{array}$ & $\begin{array}{l}\text { Enerji talep tahmini için } \\
\text { metodoloji geliştirme: } 2030 \\
\text { y1lı Türkiye örneği }\end{array}$ & $\begin{array}{l}\text { Niğde Ömer } \\
\text { Halisdemir } \\
\text { Üniversitesi } \\
\text { Mühendislik } \\
\text { Bilimleri Dergisi }\end{array}$ & Enerji & $\begin{array}{l}\text { Türkiye'de şehirlere göre, } \\
\text { elektrik enerjisi tahmini } \\
\text { senaryolar belirlenmesi }\end{array}$ & $\begin{array}{l}\text { YSA,çoklu } \\
\text { regresyon }\end{array}$ \\
\hline
\end{tabular}

\section{Türkiye'de Elektrik Enerjisi Tüketimi ve Önemi}

Sanayi devrimi sonrasında, hızla makineleşmenin başlaması ve enerjiye duyulan ihtiyacin her geçen gün artması, toplumları farklı enerji kaynakları aramaya yönlendirmiştir. Bu durum, ikincil enerji kaynağı olarak kabul edilen, elektrik enerjisini karşımıza getirmiştir (Alev ve Erdemli, 2019). Elektrik enerjisi; sanayileşme, ülkelerin kalkınması ve gelişmesi ile toplumsal refahı için büyük öneme sahiptir. Enerji tüketim miktarları ülkeler için gelişmişliğin bir göstergesi olmakla birlikte enerjinin üretim şekli ve yöntemi de çevresel etkileri açısından önem arz etmektedir (Ceylan, 2021).

Enerji kaynakları temelde birincil ve ikincil enerji kaynakları olmak üzere iki ana gruba ayrılmaktadır. Birincil enerji kaynakları, yenilenebilir ve yenilenemez kaynaklar gibi doğada bulunan kaynaklardır. Örnek vermek gerekirse, doğalgaz, petrol, güneş, rüzgâr, kömür gibi kaynaklar söylenebilir. ikincil enerji kaynakları ise, birincil yani doğal kaynakların, belli süreçlere uğrayarak işlenmesi ile ortaya çıkmaktadır. Örnek vermek gerekirse, benzin, elektrik, mazot söylenebilir. Enerji kaynakları içerinde elektrik, birincil kaynaklardan elde edilebilmesi, kullanım esnasında çevreyi kirletmemesi, iletim kolaylığı, bölünebilir olması, tüketim alanının geniş olması gibi özellikleri ile öne çıkmaktadır (Ağır ve Kar, 2010).

Yıllar içerisinde elektrik talebindeki yükseliş, talepte yaşanan değişimler ile fiyatları da arttırmıştır. Talebin gelişimini etkileyen, saatlik, günlük, mevsimsel çeşitli faktörler bulunmaktadır. Kısa vadede, çalışma saatleri sıcaklık değişimleri ve iş günleri gibi faktörler varken, uzun vadede, enerji verimliliği, gayrisafi yurtiçi hasıla (GSYH) artış oranları, sanayi üretimi gibi hususlar talep seviyelerini belirlemede etkili olmaktadır. 
Özellikle, dünyada nüfusun artması, ekonomik büyüme, kentleşmenin artması, yaşam kalitesinin yükselmesi gibi nedenlerle dünyadaki elektrik tüketimi de artış göstermektedir. Türkiye gelişen sanayisi ve artan nüfusuyla elektrik tüketim oranları her bir önceki yıla göre düzenli bir artış göstermektedir. Her sektör için tüketim oranı artmakla beraber toplam tüketimde de sektör paylarında gözle görülür derecede farklılıklar gözlemlenmektedir. Tüketim oranlarında en yüksek paya sanayi sektörü sahipken bu oranı artan şehirleşme ve gelişen altyapı iletim ağı ile ulaştırma ve mesken kullanımları takip etmektedir. Elektrik enerjisi depolanabilirliği bakımından, petrol doğalgaz kömür gibi madenlere göre daha zordur. 1990'lı yıllardan 2020'li yıllara kadar olan süreçte Türkiye'nin hızla büyüyen sanayisi ve artan nüfusla doğru orantılı olan şehirleşmeyle beraber altyapı iletim gücünün artmasıyla elektrik enerjisi bakımından dışa bağımlılığı olan ülke konumuna gelmiş bulunmaktaydı. Fakat artan bu enerji ihtiyacına karşılık dışa bağımlılığı azaltmak adına yapılan hidroelektrik, termik ve nükleer santraller ile \%62 oranında, yerli enerji elde edebilme seviyelerine ulaşmıştır.

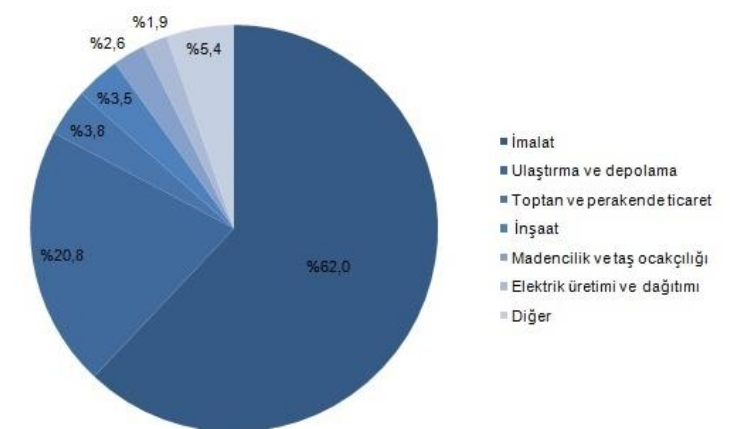

Şekil 1. 2020 Yılı İçin Enerji Tüketiminin Sektör Payları

(Kaynak: EPIASS, 2020)

2020 yılından itibaren ise, Covid-19 pandemisinin hızlı bir şekilde yayılmasıyla birlikte hem ülkemizde hem de küresel piyasalarda elektrik talebinde dikkat çekici oranda azalmalar gözlenmişir. Özellikle, kısıtlamalardan kaynaklı olarak, konutlarda artış gösteren tüketim oranının, ekonomik faaliyetlerdeki durgunluk sebebiyle, ticaret, sanayi, hizmetler sektörlerinde meydana gelen düşüşü karşılayamadığ gözlenmiştir. Piyasada zaten elektrik fazlası olduğu için, elektrik talebindeki bu düşüş, elektrik satış fiyatlarının daha da azalmasına neden olmuştur. Türkiye'nin elektrik üretiminde pandeminin de etkisiyle 2020 yılı Ocak ayından Mayıs ayına kadar düşüş gözlenmiştir. Sonrasında normalleşme sürecinin başlaması, ekonomik faaliyetlerde $\mathrm{ki}$ artış ile birlikte toparlanmanın da etkisiyle artış gözlenmiştir. İlgili dönemdeki üretim azalışı termik kaynaklı enerji santrallerinde meydana gelmiştir.

Ortalama günlük elektrik tüketimi verileri değerlendirildiğinde, 2020 yılında Nisan ve Mayıs aylarında son iki yıl için en düşük ortalama günlük tüketim miktarlarının oluştuğu gözlenmştir. 2019 y1lında günlük ortalamada 730.000 MWh ile $860.000 \mathrm{MWh}$ aralığında bir dalgalanma varken, günlük

- Trend (Uzun dönemli eğilim) (T)

- Konjonktürel (Devirsel) dalgalanmalar (C) ortalama elektrik tüketimi 2020 yılı Nisan ayında $637.686 \mathrm{MWh}$ ve Mayıs ayında $576.438 \mathrm{MWh}$ olarak gerçekleşmiştir. Bu düşüşlerdeki en büyük etkenin sanayi tesislerindeki yavaşlama olduğu belirtilmektedir. Haziran ayına gelindiğinde ise, normalleşme ile birlikte günlük ortalama elektrik tüketimi $750.000 \mathrm{MWh}$ seviyelerine kadar yükselmiştir. Temmuz ve Ağustos aylarında iklim şartlarının etkisi ve normalleşme adımlarının genişlemesi ile ortalama günlük elektrik tüketimi bir önceki yılın aynı seviyelerine gelmiştir (Enerji görünümü, 2020).

\section{Materyal ve Metot}

Türkiye 'de elektrik kullanımına yönelik yapılan bu talep tahmin çalışmasında verilerin doğruluğu ve güvenilirliği çalışmanın seyri ve sonuçları açısından oldukça önemlidir. $\mathrm{Bu}$ yüzden çalışmada, Türkiye istatistik kurumu resmi sayfasından 1970-2019 yılları arasındaki Tükrkiye'de ki elektrik tüketim verileri ele alınarak analiz gerçekleştirilmiştir. İki tahmin yönteminin karşılaştırılması ile izlenen metodolojinin güvenilirliğinin ölçülmesi desteklenmiştir. Seçilen metodoloji, daha önce literatürde bilinmekte sıklıkla tercih edilmektedir. Buna karşın yapılan analizin güncel olması yazına katkı sunmaktadır. Seçilen yöntemlerde tek değişkenler yerine, güçlü ilişkisi olduğu düşünülen veri setlerinin kullanılması ile daha sağlıklı sonuçlar elde edilmiştir. ARIMA, dinamik yapısı nedeniyle elektrik tüketimi tahmininde kullanılabilecek en iyi modellerden biridir. Ayrıca tercih edilen yöntemlerin kullanımı kolay, göreceli olarak iyi sonuç vermekte ve kullanıcılar için anlaşılırdır.

\subsection{Talep Tahmini}

Talep tahmini, bir ürünün veya ürünlerin talebini doğru bir şekilde hesaplamaktır. Hesaplama yapmak için birçok yöntem kullanılmaktadır. Talep tahmini hemen hemen tüm sektörlerde ve iş planlamalarında karşılaşacağımız bir kavramdır. Geniş sektör yelpazesinin bulunduğu bu zamanlarda talep tahmini işletmeler için hem mevcut durumunu geliştirmek ya da korumakta hem de karlılık oranını arttırıp, zarar etmemekte büyük önem teşkil eder. Kalitatif ve kantitatif yöntemler olmak üzere iki gruba ayrılır. Zaman serisi ve regresyon analizleri kantitatif yöntemlere örnek verilebilir.

\subsubsection{Zaman Serisi Analizi}

Belirli bir zaman aralığında bir veya birden çok değişenin ölçülmesiyle bulunan dizili veri grubuna "zaman serisi" denir. Zaman serileri sayesinde, eskiye dönük bulgulardan gelen sonuçlar kullanarak gelecek zamanı tahmin etmek mümkündür. Zaman serileri, birçok zaman faktörünün etkisi altında dalgalanır. $\mathrm{Bu}$ dalgalanmalar; ekonomi, toplum, nüfus, psikoloji vb. gerçeklerden dolayı, çeşitli faktörler farklı doğrultuda ve yoğunluklarda etkileyecektir. Zaman serisinin en temel niteliği, gözlemlerdeki değişikliklerin genellikle bu faktörlerin bir kombinasyonunun sonucu olmasıdır. Bu faktörler aşağıdaki dört ana gruba ayrilabilir.

- Mevsimsel dalgalanma (S)

- Tesadüfî dalgalanmalar (I)

Yukarıda verilmiş olan faktörlere ait zaman serisinin yaygın olarak aşağıdaki denklem 1 ile gösterilebiliriz:

$$
\mathrm{Y}=\mathrm{T}+\mathrm{S}+\mathrm{C}+\mathrm{I}
$$


Zaman serisinin gelecekteki değerini tahmin etmek için kullanılan yöntem; bu, tahminin amacına, zaman serisinin türüne ve öğelerine, geçmiş verilerin miktarına ve tahmin süresinin genişliğine göre değişiklik gösterebilir. Günümüzde geliştirilmiş yazılımlar sayesinde en uygun yöntem otomatik olarak belirlenebilmektedir. Zaman serileri analizinde şimdiye kadar kullanılan yöntemler aşağıda gösterilmiştir;

- Box-Jenkins (ARIMA)

- Üstel Düzleştirme

- Hareketli Ortalamalar

- Mekanik Tahmin

- Uyarlayıcı Arındirma

- $\quad$ Trend Analizi

- Mevsimsel Dalgalanmalar ve Trende Oranlama Yöntemi

\subsubsection{Regresyon}

Karma yöntemler içerisinde bulunan regresyon analizi ile bir değişkenin (bağımlı ya da bağımsız) gelecekteki durumunu tahmin etmenin yanı sıra bir ya da birden daha fazla değişken arasındaki ilişkiyi matematiksel model olarak yazılmasıdır. Bağımsız değişken (etken değişken, açıklayıcı değişken, bağımlı değişkeni etkilediği düşünülen değişkendir Bağımlı değişken (yanıt değişkeni, açıklanan değişken, sonuç değişkeni) bağımsız değişkenden etkilendiği kabul edilen değişkendir. (Yergök ve Acı, 2019).

$\mathrm{Bu}$ analiz yönteminde; bir bağımsız kullanılarak analiz yapılıyorsa buna tek değişkenli regresyon diğer bir deyişle basit regresyon, birden fazla bağımsız kullanılarak analiz yapılıyorsa çok değişkenli regresyon analizi diye adlandırılır. Regresyon

Tablo 2. Elektrik tüketim miktarları ve bağımsız değişken veri tablosu (Kaynak: TÜIKK 2019)

\begin{tabular}{|l|l|l|l|l|l|l|}
\hline Yıl & Tüketim(Gwh) & Nüfus & $\begin{array}{l}\text { Kişi Başı } \\
\text { Gelir(\$) }\end{array}$ & $\begin{array}{l}\text { Satılan } \\
\text { Konut } \\
\text { Sayısı }\end{array}$ & $\begin{array}{l}\text { Beyaz Eşya } \\
\text { Sayısı }\end{array}$ & $\begin{array}{l}\text { İ Yeri } \\
\text { Sayısı }\end{array}$ \\
\hline $\mathbf{2 0 0 7}$ & 155135,00 & 70586256,00 & 9656,00 & 327000,00 & 6215997,00 & 2581823,00 \\
\hline $\mathbf{2 0 0 8}$ & 161948,00 & 71517100,00 & 10931,00 & 427105,00 & 6121842,00 & 2617436,00 \\
\hline $\mathbf{2 0 0 9}$ & 156894,00 & 72561312,00 & 9039,00 & 555184,00 & 6324802,00 & 2631085,00 \\
\hline $\mathbf{2 0 1 0}$ & 172051,00 & 73722988,00 & 10560,00 & 607098,00 & 6439761,00 & 2678787,00 \\
\hline $\mathbf{2 0 1 1}$ & 186100,00 & 74724269,00 & 11205,00 & 708275,00 & 6728520,00 & 2737278,00 \\
\hline $\mathbf{2 0 1 2}$ & 194923,00 & 75627384,00 & 11588,00 & 701621,00 & 6839646,00 & 2800060,00 \\
\hline $\mathbf{2 0 1 3}$ & 198045,00 & 76667864,00 & 12519,00 & 1157190,00 & 6956821,00 & 2847725,00 \\
\hline $\mathbf{2 0 1 4}$ & 207375,00 & 77695904,00 & 12112,00 & 1165381,00 & 6970878,00 & 2888180,00 \\
\hline $\mathbf{2 0 1 5}$ & 217312,00 & 78741053,00 & 11019,00 & 1289320,00 & 7090051,00 & 2941233,00 \\
\hline $\mathbf{2 0 1 6}$ & 231203,70 & 79814871,00 & 10883,00 & 1341453,00 & 7469796,00 & 2981381,00 \\
\hline $\mathbf{2 0 1 7}$ & 249022,60 & 80810525,00 & 10602,00 & 1409314,00 & 8533013,00 & 3100412,00 \\
\hline $\mathbf{2 0 1 8}$ & 258232,00 & 82003882,00 & 9632,00 & 1375398,00 & 7110193,00 & 3160371,00 \\
\hline $\mathbf{2 0 1 9}$ & 257273,10 & 83154997,00 & 9042,00 & 1348729,00 & 6655155,00 & 3198286,00 \\
\hline
\end{tabular}

Elde edilen sayısal veriler sonucunda Excel sayfamızda yer alan Veri sekmesindeki veri çözümlemesinden regresyonu analizinde, belirli aralıktaki geçmiş dönem verileri ile bazı formüller geliştirilir. Geçmiş veriler ne kadar sürekli ve düzenli ise tahminlerin tutarlılık oranı da o kadar yüksektir. Fakat, bağımsız değişken değerleri farklılık ve düzensizlik gösteriyorsa, tahmin hatası da yüksek olacaktır. İki değişkenin arasındaki ilişkinin doğrusal olduğu varsayılırsa, denklem 2 şeklinde gösterilir ve bağımsız değişkenin değeri yerine yerleştirilerek tahmin değeri elde edilir.

$(\mathrm{Y}=\mathrm{a}+\mathrm{bx})$

\subsection{Verilerin Elde Edilmesi}

TÜİK'ten (Türkiye İstatistik Kurumu) almış olduğumuz 1970-2019 yılları arasındaki Türkiye'deki elektrik tüketim oranlarını referans alarak incelenmiștir. Verilerin analiz edilmesinde; E-views ve Microsoft Excel programları tercih edilmiştir.

\subsection{Regresyon Modelinin Oluşturulması}

Öncelikle 2007-2019 arasındaki TUİK'den elektrik tüketim verileri elde edilmiştir. Elde edilen veriler üzerinde elektrik tüketimini etkileyebilecek olan değişkenler belirlenmiştir. Nüfus, konut sayısı, kişi başına düşen milli gelir, beyaz eşya kullanımı ve

iş yeri sayılarının elektrik tüketimi üzerinde değişiklikler sağlanacağını düşünüldüğünden, bu veriler bağımsız değişken olarak belirlenmiştir. seçerek veriler arasında regresyon analizinin yapılması sağlanmıştır. Yapılan denemeler sonucunda gerçeğe en yakın ve 
$\mathrm{R}^{\wedge} 2$ değerinin en yüksek sonucunu veren formülün beyaz eșya kullanımı ve iş yeri sayısı arasında olduğu belirlenmişsir.

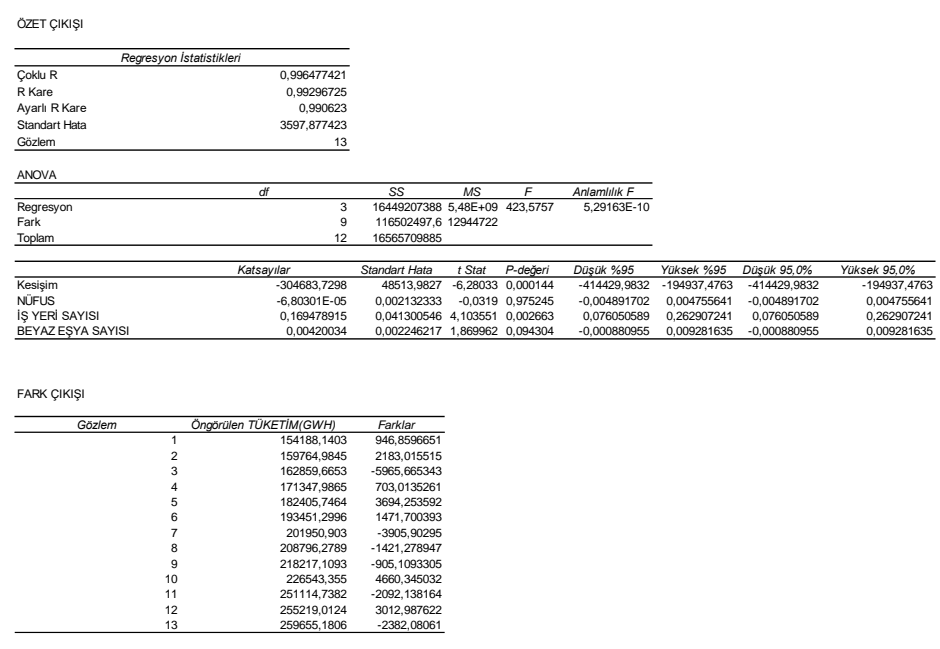

Şekil 2. Regresyon Analizi Sonucu

Şekil 2'ye göre Beyaz Eşya Kullanım Miktarı ve İş Yeri Sayısı'nın P değerinin 0.05 'ten düşük olması bu değişkenlerin, bağımlı değişken olan elektrik tüketimine etkisi olduğunu göstermektedir. Elimizdeki verileri Excel dosyası üzerine işleyerek 'Veri' sekmesinden veri çözümleme kısmına girip regresyon formülünü seçtikten sonra Excel'in otomatik olarak bize regresyon sonuçlarını verdiği söylenebilir. Bağımsız değiş̧kenlerimiz kullanılan beyaz eşya sayısı ve iş yeri sayısıdır. $\mathrm{Bu}$ değişkenlerinde ileri zamanlı talep tahmini yapılmıştır. Katsayıların altındaki rakamlar bize değişkenlerimizin formüldeki katsayılarını ve sabit sayısını vermektedir. $\mathrm{Bu}$ doğrultuda ilerleyerek regresyon denklemi (3) oluşturulmuştur.

Tüketilen elektrik miktarı $=-306161,640+0,00419643 *$ Beyaz eşya sayısı $+0,168179 *$ İş yeri sayısı

Denklem 3'ü kurduktan sonra talep tahmin yapılması mümkündür. İleri zamanlı öngörmüş olduğumuz beyaz eşya ve iş yeri sayılarını formülde yerine yazıldığında çıkan sonuç, o yıla ait olan elektrik tüketim miktarının tahminini vermektedir. Talep tahmini 2035 yılı için hesapladığımızda; elde edilen bilgiler Tablo 3 , Şekil 3 ve Şekil 4' de paylaşılmıştır.

Tablo 3. 2035 yılı için talep tahmini sonucu

\begin{tabular}{|l|l|l|l|}
\hline Yıl & Beyaz eşya sayısı & İş yeri sayısı & Tahmin \\
\hline 2007 & 6215997 & 2581823 & 154132 \\
\hline 2008 & 6121842 & 2617436 & 159726,3 \\
\hline 2009 & 6324802 & 2631085 & 162873,5 \\
\hline 2010 & 6439761 & 2678787 & 171378,4 \\
\hline 2011 & 6728520 & 2737278 & 182427,1 \\
\hline 2012 & 6839646 & 2800060 & 193452 \\
\hline 2013 & 6956821 & 2847725 & 201960 \\
\hline 2014 & 6970878 & 2888180 & 208822,7 \\
\hline 2015 & 7090051 & 2941233 & 218245,2 \\
\hline 2016 & 7469796 & 2981381 & 226590,8 \\
\hline 2017 & 8533013 & 3100412 & 251071,1 \\
\hline 2018 & 7110193 & 3160371 & 255184,2 \\
\hline 2019 & 6655155 & 3198286 & 259651,1 \\
\hline 2020 & 6766989 & 3253965 & 269484,5 \\
\hline
\end{tabular}

\begin{tabular}{|l|l|l|l|}
\hline 2021 & 6853192 & 3307805 & 278901 \\
\hline 2022 & 6922734 & 3362130 & 288329,1 \\
\hline 2023 & 7213137 & 3412933 & 298091,8 \\
\hline 2024 & 7344786 & 3467985 & 307902,9 \\
\hline 2025 & 7394986 & 3522742 & 317322,5 \\
\hline 2026 & 7448776 & 3577600 & 326774,2 \\
\hline 2027 & 7504438 & 3632653 & 336266,5 \\
\hline 2028 & 7556580 & 3687523 & 345713,3 \\
\hline 2029 & 7604055 & 3742437 & 355147,9 \\
\hline 2030 & 7656725 & 3797369 & 364607,4 \\
\hline 2031 & 7700260 & 3852314 & 374030,7 \\
\hline 2032 & 7752513 & 3907269 & 383492,2 \\
\hline 2033 & 7804746 & 3962231 & 392954,9 \\
\hline 2034 & 7856715 & 4017198 & 402417,3 \\
\hline 2035 & 7908648 & 4072170 & 411880,3 \\
\hline
\end{tabular}

ÖZET ÇIKIŞI

\begin{tabular}{|c|c|c|c|c|c|}
\hline \multicolumn{2}{|c|}{ Regresyon Istatistikleri } & & & & \\
\hline Çoklu R & 0,996477022 & & & & \\
\hline R Kare & 0,992966455 & & & & \\
\hline Ayarlı R Ki & 0,991559745 & & & & \\
\hline Standart $\mathrm{H}$ & 3413,439228 & & & & \\
\hline Gözlem & 13 & & & & \\
\hline ANOVA & & & & & \\
\hline & $d f$ & SS & $M S$ & $F$ & Anlamllık $F$ \\
\hline Regresyon & 2 & $1,6449 \mathrm{E}+10$ & $8,22 \mathrm{E}+09$ & 705,879 & $9 \quad 1,72 \mathrm{E}-11$ \\
\hline Fark & 10 & 116515674 & 11651567 & & \\
\hline Toplam & 12 & $1,6566 \mathrm{E}+10$ & & & \\
\hline
\end{tabular}

Katsayılar Standart Hata $t$ Stat $\quad P$-değeri Jüşük \%95'üksek \%9!üşük 95,0\%iksek 95,0\% \begin{tabular}{lllllllll}
\hline Kesissim & $-306161,64$ & 13674,167 & $-22,3898$ & $7,1 \mathrm{E}-10$ & -336630 & -275694 & -336630 & -275694
\end{tabular} $\begin{array}{lllllllll}\text { BEYAZEş } & 0,004196436 & 0,0021279 & 1,972099 & 0,076876 & -0,00054 & 0,008938 & -0,00054 & 0,008938\end{array}$ \begin{tabular}{lllllllll} 
iş YERI S, & 0,168179092 & 0,00642479 & 26,17658 & $1,52 E-10$ & 0,153864 & 0,182494 & 0,153864 & 0,182494 \\
\hline
\end{tabular}

FARK ÇIKIŞI

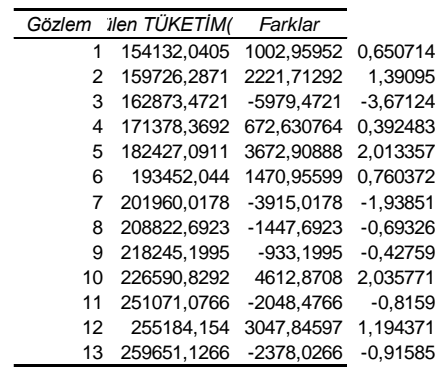

$$
-0,02434
$$

Şekil 3. Regresyon Analizi Sonucu

\section{7-2035 Tahmin Grafiği}

500000,00

400000,00

300000,00

200000,00

100000,00

0,00

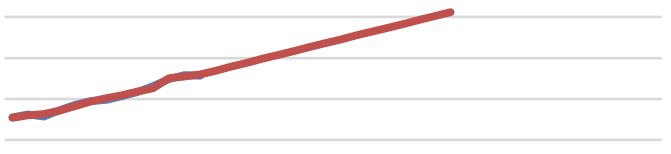

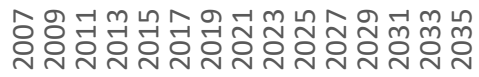

TÜKETIM(GWH)

TAHMIN

Şekil 4. 2007-2035 yılları arasındaki regresyon analizi yöntemine göre talep tahmin grafiğ $i$
100 
Tablo 4. Regresyon Analizi Hata Değerleri

\begin{tabular}{|c|c|}
\hline 0,169755 & Hata \\
\hline 0,013058 & Ortalama hata \\
\hline 1,305804 & Mape \\
\hline
\end{tabular}

\subsection{Zaman serisi Eview Ortamında Modelin Oluşturulması}

Eviews programında, yeni dosya oluşturulduktan sonra, 1970-2019 arasındaki TUİK'den alınan elektrik tüketim verileri programa aktarılmıştır. Oluşan dosyaya Eviews otomatik olarak ser01 adlı bir isim vermiştir. Bu ser01 dosyası açıldığında, sekmede Proc sekmesi kullanılarak, Automatic ARIMA Forecasting seçeneği ile Şekil 5 'de görüldüğü üzere, modelimizin p, d, q yani AR-I-MA değerleri hesaplanmıştır.

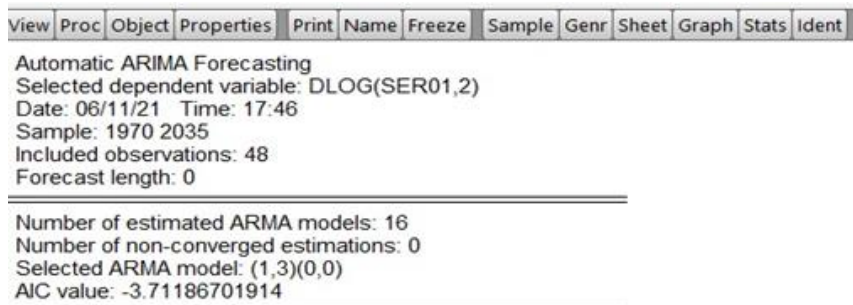

Number of estimated ARMA models: 16

Number of non-converged estimations: 0

Selected ARMA model: $(1,3)(0,0)$

AIC value: -3.71186701914

Şekil 5. Otomatik Arıma Ölçüm Sonuçları (p,d,q değerleri)

Şekil 5'te ki Dependet variable bize almamız gereken farkın 2 olduğunu belirtmektedir. ARMA modeli ise bize $p$ ve $q$ değerlerini verir. Buradan sonuç olarak çıkan; q değerinin 3 olduğu ve aynı zamanda $p$ değerinin de 0 olduğu görülmektedir. $\mathrm{Bu}$ çıkan değerlere göre, komut verilmesi gerekmektedir. Aşağıda şekil 6' da yer alan komut sonucunda ise, program bizlere test sonuçlarını göstermektedir.

12 EViews - [Equation: UNTITLED Workfile: UNTITLED:UntitledN]

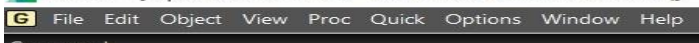

LS D(SER01,2) C MA(2) MA(3)

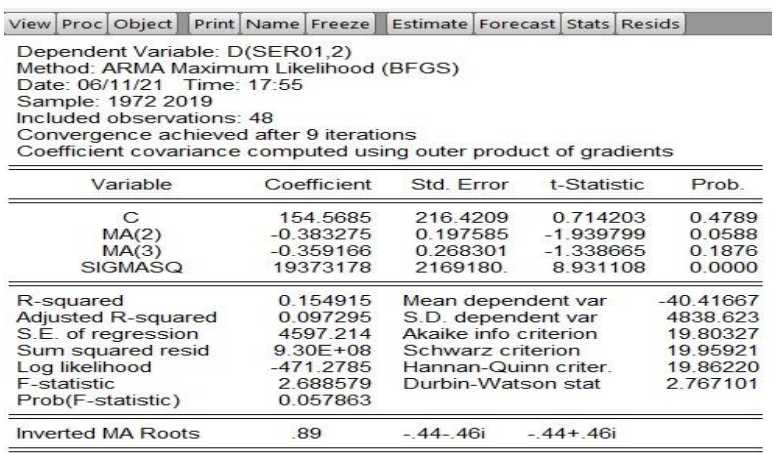

Şekil 6. p,d,q değerlerine göre E-views formülasyon hesaplamalart

Şekil 6'da forecast sekmesinde açılan ekranda tahmin yapmak istediğimiz yıl aralıklarını girerek ileriye dönük talep tahminlerimiz, buna bağlı olarak grafikler ve hata değerleri Tablo 5, Şekil 7, Şekil 8'de elde edilmiştir.

\begin{tabular}{|c|c|c|}
\hline & SER01F & SER01 \\
\hline 2000 & 103975.3 & 98296 \\
\hline 2001 & 109593.4 & 97070 \\
\hline 2002 & 115366.0 & 102948 \\
\hline 2003 & 121293.2 & 111766 \\
\hline 2004 & 127374.9 & 121142 \\
\hline 2005 & 133611.3 & 130263 \\
\hline 2006 & 140002.2 & 143071 \\
\hline 2007 & 146547.6 & 155135 \\
\hline 2008 & 153247.7 & 161948 \\
\hline 2009 & 160102.3 & 156894 \\
\hline 2010 & 167111.5 & 172051 \\
\hline 2011 & 174275.2 & 186100 \\
\hline 2012 & 181593.5 & 194923 \\
\hline 2013 & 1890664 & 198045 \\
\hline 2014 & 196693.8 & 207375 \\
\hline 2015 & 204475.8 & 217312 \\
\hline 2016 & 2124124 & 231204 \\
\hline 2017 & 220503.6 & 249023 \\
\hline 2018 & 228749.3 & 258232 \\
\hline 2019 & 237149.6 & 257273 \\
\hline 2020 & 245704.5 & NA \\
\hline 2021 & 254413.9 & NA \\
\hline 2022 & 263277.9 & NA \\
\hline 2023 & 272296.4 & NA \\
\hline 2024 & 281469.6 & NA \\
\hline 2025 & 290797.3 & NA \\
\hline 2026 & 300279.5 & NA \\
\hline 2027 & 309916.4 & NA \\
\hline 2028 & 319707.8 & NA \\
\hline 2029 & 329653.8 & NA \\
\hline 2030 & 339754.3 & NA \\
\hline 2031 & 350009.4 & NA \\
\hline 2032 & 360419.1 & NA \\
\hline 2033 & 370983.3 & NA \\
\hline 2034 & 381702.2 & NA \\
\hline 2035 & 392575.5 & NA \\
\hline
\end{tabular}

Tablo 5. 2000- 2035 yılları arasındaki E-views tahmin sonuçları

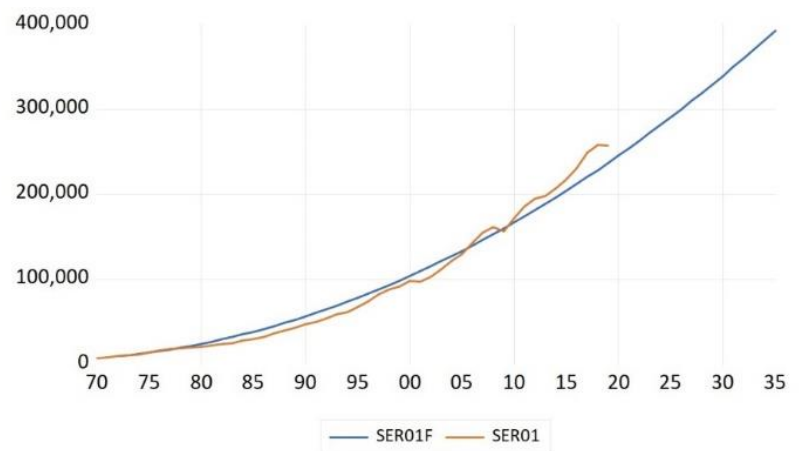

Şekil 7. 1970-2035 yılları arasındaki zaman serisi analizi yöntemine göre elektrik tüketim talep tahmin ve gerçek veriler

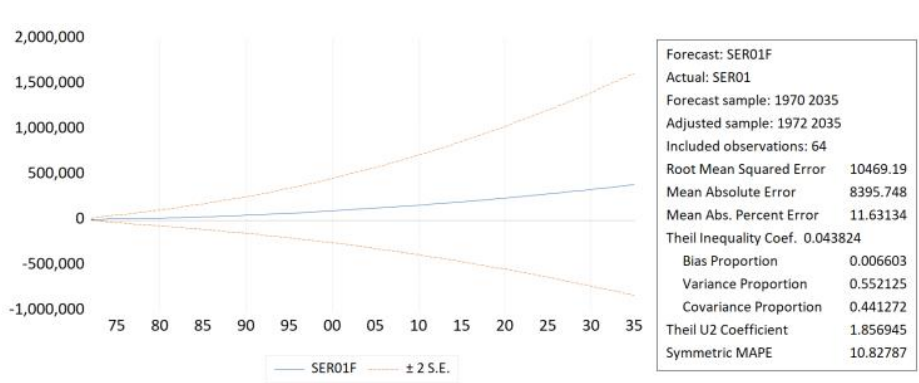

Şekil 8. Tahmin ve gerçek değerler grafiği (Hata Değerleri)

\section{Araștırma Sonuçları ve Tartışma}

Talep tahmin yöntemleri ile geçmiş dönem verilerinden faydalanılarak gelecek dönemler için uzun veya kısa vadeli 
tahminler ile kurumların yönünü belirlemede, şirketlerin varlıklarını, vizyonlarını ve müşterilerin ihtiyaçlarını karşılaşması doğrultusunda aktif rol oynadığı bilinmektedir. Bu nedenle sağlıklı öngörülerde bulunmanın veya belirsiz gelecek koşullarını tahmin etmenin, alınacak kararların doğruluğu açısından oldukça önemli olduğu söylenebilir.

$\mathrm{Bu}$ araştırmanın amacı, talep tahmini üzerine şimdiye kadar yapılan araştırmaları göz önünde bulundurarak, geçmiş dönem elektrik tüketim verilerini referans alarak ileriye dönük tahminler yapmaktır. Buradaki tahminlerin önemliliği elektriğin fazla miktarda depolanamadığından ve ileriye dönük tüketim tahminlerini baz alarak ihtiyaca göre önceden aksiyon alabilme imkanı sunmakta ve bu aksiyon doğrultusunda büyük güç santralleri, elektrik jeneratörleri ve rüzgar gülleri gibi elektrik üretim aşamalarının önceden planlanarak uygulanmasını sağlamaktadır.

1970-2019 elektrik tüketim verileri kullanılarak tüketici talep tahmini analizi yapılmıştır. Bu veriler ile Excel üzerinde beyaz eşya kullanım sayısı ve iş yeri sayısının elektrik tüketimi arasındaki bağlılık oranı hesaplanarak regresyon analizi ve 2035 yılına kadar tüketilebilecek elektrik miktarı hesaplanmıştır. Aynı veriler doğrultusunda Eviews programında da ARIMA'nın IMA modeli kurulmuştur. Kurulan bu model üzerinden 2035 tahminlerinde bulunulmuştur. Regresyon analizi ve zaman serisi grafiklerini karşılaştırma imkânı sunulmuştur (Tablo 6).

Tablo 6. Regresyon analizi ve zaman serisi karşılaştırmalı hata dĕgerleri grafĭg $i$

\begin{tabular}{|l|l|l|}
\hline & $\begin{array}{l}\text { Regresyon } \\
\text { Sonuçları }\end{array}$ & $\begin{array}{l}\text { Zaman Serisi } \\
\text { Sonuçları }\end{array}$ \\
\hline MSE & 0,169755 & 10469,19 \\
\hline MAPE & 1,305804 & 11,63134 \\
\hline MAE & 0,013058 & 8395,748 \\
\hline
\end{tabular}

MAPE kriteri yüzdesel olarak tahmin hatalarını belirtmesi ve yalnız kullanılabiliyor olması sebebi ile, diğer kriterlere üstünlüğü varsayılmaktadır. Bu yüzden sonuç değerlendirmelerinde MAPE değerlerinin karşılaştırması üzerinden değerlendirmelere geniş yer verilmiştir. Regresyon Analizi sonucumuzu ele alarak, yüksek $\mathrm{R}^{\wedge} 2$ değerine sahip olması elde etmiş olduğumuz formülün güvenilir olduğunu bize söylemektedir. Ayarlı $\mathrm{R}^{\wedge} 2$ değerinin 0,99156 olması beyaz eşya ve iş yeri sayılarının elektrik tüketimindeki değerlerini \%99,156 değerinde etkilemektedir. Bağımsız değişkenlerimizin P değerlerinin \%5 ten küçük olması bağımlı değişken üzerinde etkili olduklarını göstermektedir. Zaman Serisi sonuçları ele alınırsa, Şekil 8'de yer alan MAPE değerinin \%10'un altında olan modellerde yüksek doğruluk derecesi olduğu bilinmektedir. Yapmış olduğumuz zaman serisinde bu değerin 11.63 olduğu gözlemlenmektedir. Mape değerinin \%10 ile \%20 arasında olması doğru tahmin modelleri arasında sınıflandırıldığından analiz sonucumuza göre kabul edilebilir ve doğru tahmin modeli olarak ele alınabilmektedir. Fakat Regresyon analizindeki MAPE değerinin doğruluk oranı zaman serisine göre daha fazla olduğu için yapmış olduğumuz çalışmada zaman serisi analizinin gerçek değerlere en yakın yüksek derecede verimli sonuçlar elde edildiği kanısına varılmıştır. Tablo 4 ve Şekil 8'de analiz sonuçlarına göre, regresyon analizinin MAPE değeri \%1.30 iken, zaman serisinde bu oran \%11.63'tür. Buda regresyon analizi tahmin değerlerinin uygulanabilirlik açısından daha doğru sonuçlar vereceğini bize göstermektedir. Yapmış olduğumuz bu çalışmada regresyon ve zaman serisi analizleri sonucunda 2035 yılında regresyon analizi tahminine göre tüketilecek olan elektrik miktarı $411880 \mathrm{GWh}$ iken, zaman serisine göre bu sayı 392575.5 GWh'tır. TÜİK tarafından alınan var olan değerler ile regresyon ve zaman serisi sonucunda yapmış olduğumuz talep tahmin sonuçlarının birbirlerine yakın olduğu gözlemlenmektedir. Mevcut değer ile regresyon ve zaman serisi analizi çalışması sonrasında, birbirine yakın değerler elde etmemiz kullandığımız yöntemlerin bizi doğru sonuca ulaştırmada etkili olduğu gözlemlenmektedir.

Yapılan talep tahmini sonuçlarımıza bakarak öneride bulunmamız gerekirse, yapılan talep tahminlerinin ilerleyen dönemlerde gerçekleşen veriler ile karşılaştırarak yapılan tahminlerin tutarlılığ 1 kontrol edilmelidir. Yapılan tahminlerin tutarlılığından emin olduktan sonra ileriye yeni santral ihtiyaçları belirlenmeli ve gerekli aksiyonlar alınmalıdır. Tüketim konusunda insanların bilinçlendirilmesi ve kaynakların doğru kullanılması ve israfın önlenmesi amaçlanmalıdır. Bakanlık tarafindan açıklanan Türkiye'nin 2019 yılı elektrik tüketiminin 257273,1 GWh olduğu bilinmektedir. Bu rakamın önümüzdeki y1llarda düşürülebilmesi için bu bağlamda, Türkiye elektrik piyasasındaki elektrik tüketim tahminine dikkat edilmesi, ilerleyen zamanlar için daha etkili planların yapılması, elektrik sektöründeki kayıp kaçaklarla etkin bir şekilde mücadele edilmesi elektrik üretim kaynaklarının çeşitlendirilmesi ve kalkınmanın önünün açılması önemle arz etmektedir.

\section{Kaynakça}

Ağır, H. \& Kar, M., 2010, "Türkiye'de elektrik tüketimi ve ekonomik gelişmişlik düzeyi ilişkisi: yatay kesit analizi". Sosyoekonomi, 6(12), 149-175.

Alev, N. \& Erdemli, M., 2019, "Elektrik enerjisi tüketimi ve ekonomik büyüme ilişkisi: avrupa birliği ülkeleri ve türkiye için bir analiz", Assam Uluslararası Hakemli Dergi, 6 (15), 88-111.

Altınay, G., 2010, "Aylık Elektrik Talebinin Mevsimsel Model ile Orta Dönem Öngörüsü.", Enerji, Piyasa ve Düzenleme: 1-23.

Al-Hafid, M. S., \& Al-maamary, G. H. (2012). Short term electrical load forecasting using holtwinters method. AL Rafdain Engineering Journal, 20(6), 15-22.

Bulut, M. \& Başoğlu, B. (2017). Kısa Dönem Elektrik Talep Tahminleri İçin Yapay Sinir Ağları ve Uzman Sistemler Tabanlı Hibrid Tahmin Sistemi Geliştirilmesi. Gazi Üniversitesi Mühendislik Mimarlık Fakültesi Dergisi, 32 (2)

Ceylan, H., (2021). Çevresel Etki Değerlendirmesi Uygulamalarında Enerji Sektörü Analizi, Avrupa Bilim ve Teknoloji Dergisi, (27), 237-242.

Çiçek, C., \& Lecuna, H. K. S. (2019). Türkiye'deki Bölgelerin Elektrik Tüketim Etkinliklerinin Veri Zarflama Analizi ile Değerlendirilmesi. Akıllı Ulaşım Sistemleri ve Uygulamaları Dergisi, 2(2), 27-48.

Demirel, Ö., Kakilli, A., \& Tektaş. M., 2010, "ANFIS ve ARMA modelleri ile elektrik enerjisi yük tahmini", Gazi Üniversitesi Mühendislik Mimarlık Fakültesi Dergisi: 601-610.

Enerji görünümü, 2020. Son Erişim tarihi: 07.09.2021. https://www.tskb.com.tr/i/assets/document/pdf/enerji-sektorgorunumu-2020.pdf.

Es, H. A., Kalender F., \& Hamzaçebi, Ç., 2014, "Yapay sinir ağları ile Türkiye net enerji talep tahmini”, Gazi Üniversitesi Mühendislik Mimarlık Fakültesi Dergisi, 29(3), 495 - 504 
Erdoğdu, E., 2007, "Electricity demand analysis using cointegration and ARIMA modelling: A case study of Turkey." Energy Policy 35: 1129-1146.

Erkınay Özdemir, M. (2021). Yapay Sinir Ağları Kullanılarak Orta Dönem Elektrik Enerjisi Tüketim Tahmini: İskenderun Örneği . Avrupa Bilim ve Teknoloji Dergisi , Ejosat Special Issue 2021 (ICAENS), 489-492 .

Hamzaçebi, C., 2007, “Forecasting of Turkey's net electricity energy consumption on sectoral bases", Energy Policy, cilt 35, ss. 2009-2016.

Hussain, A., \& Rahman, M,. \& Memon, J. A., 2016, "Forecasting electricity consumption in Pakistan: the way forward," Energy Policy, Elsevier, vol. 90(C), pages 73-80.

Jiang, W., Wu, X., Gong, Y., Yu, W., \& Zhong, X., 2020, "HoltWinters smoothing enhanced by fruit fly optimization algorithm to forecast monthly electricity consumption", Energy, 193, 116779.

Karaca, C., \& Karacan, H. (2016). Çoklu regresyon metoduyla elektrik tüketim talebini etkileyen faktörlerin incelenmesi. Selçuk Üniversitesi Mühendislik, Bilim ve Teknoloji Dergisi, 4(3), 182-195.

Kheirkhah, A., Azadeh, A., Saberi, M., Azaron, A., \& Shakouri, H. (2013). Improved estimation of electricity demand function by using of artificial neural network, principal component analysis and data envelopment analysis. Computers \& Industrial Engineering, 64(1), 425-441.

Liu, N., Babushkin, V., \& Afshari, A. (2014). Short-term forecasting of temperature driven electricity load using time series and neural network model. Journal of Clean Energy Technologies, 2(4), 327-331.

Mahmutoğlu, M., \& Öztürk, F. (2015), “Türkiye elektrik tüketimi öngörüsü ve bu kapsamda geliştirilebilecek politika önerileri”, In EY International Congress on Economics II (EYC2015), November 5-6, 2015, Ankara, Turkey (No. 239). Ekonomik Yaklasim Association.

Ozoh, P., Abd-Rahman, S., Labadin, J., \& Apperley, M. (2014). A comparative analysis of techniques for forecasting electricity consumption. International journal of computer applications, $88(15)$

Özkan, E. , Güler, E. \& Aladağ, Z. (2020). Elektrik enerjisi tüketim verileri için uygun tahmin yöntemi seçimi . Endüstri Mühendisliği,31(2),198-214.

Son, H., \& Kim, C., 2017, "Short-term forecasting of electricity demand for the residential sector using weather and socialvariables", Resources, conservation and recycling, 123, 200-207.

Taylor, J. W., \& McSharry, P. E., 2008, "Short-term load forecasting methods: An evaluation based on european data", IEEE Transactions on Power Systems, 22(4), 2213-2219.

Toker, A.C., \& Korkmaz. O., 2009, "'Türkiye kısa süreli elektrik talebinin saatlik olarak tahmin edilmesi.", Erişim tarihi: 07 Eylül 2021.

Toros, H. \& Aydın, D. (2018). Prediction of Short-Term Electricity Consumption by Artificial Neural Networks Using Temperature Variables . Avrupa Bilim ve Teknoloji Dergisi , (14), 393-398 .

Ülkü, H. \& Yalpır, Ş. (2021). Enerji talep tahmini için metodoloji geliştirme: 2030 yılı Türkiye örneği . Niğde Ömer Halisdemir Üniversitesi Mühendislik Bilimleri Dergisi, 10 (1) , 188-201.

Yergök, D. \& Ac1, M. (2019). Toplu Yemek Üretiminde Günlük Talep Tahmini için Alternatif Bir Yaklaşım: Öğrenci Regresyon. European Journal of Science and Technology, (Özel Say1), 64-73.
Yüksel Haliloğlu, E. \& Tutu, B. E., 2018, "Türkiye için kısa vadeli elektrik enerjisi talep tahmini”, Yaşar Üniversitesi EDergisi , 13 (51) , 243-255. 